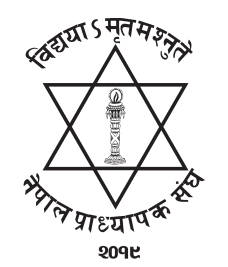

NJ: NUTA

\title{
Social Life and Everyday Experience of Ethnic People in Urban Setting: An Anthropological Overview of Darai People of Damauli Bazaar
}

\author{
Tika Raj Kaini ${ }^{1}$, Bishista Shree ${ }^{2}$ \\ ${ }^{1}$ Department of Anthropology, Trichandra Multiple Campus, Tribhuvan University, Nepal \\ ${ }^{2}$ Department of Rural Development, Trichandra Multiple Campus, Tribhuvan University, Nepal \\ Corresponding author Email: trkaini@yahoo.com
}

\begin{abstract}
This paper investigates the issues of urban development and the quality of life of Darai people with the process of modernization. It explores the process of urbanization and distribution of land after the planning in urban area. The paper highlights issues of ethnic solidarity, tensions and situation of utilization of modern facilities among the Darai ethnic population of Damauli Bazaar. Findings of this research point out the overall dissatisfaction with inadequate facilities, fear of ethnic tensions, exclusion from social processes and division in ethnic solidarity among the studied population.
\end{abstract}

Key words: Ethnic People, Ethnic Tension, Exclusion, Marginalization, Urban Development

\section{Introduction}

Urban development has a long history in the world and in Nepal also. It demands for more land for infrastructure, economic activities and residential accommodation following the opening up of the economy. In the process, the land occupied by the poor ethnic people in urban area become highly vulnerable to repossession by public authorities for real estate development and infrastructure projects (Roy, 2008). There have been increasingly strident protests over the takeover of land in rural and peri-urban areas and involuntary displacement arising out of redevelopment and infrastructure upgrading in built-up urban areas, however due attention from academicians and planners is still lacking to these issues. Along with the growing literature on urban development-induced displacement and resettlement (UDIDR) planned and implemented from above, and its more general impacts on the affected population, there has been increasing interest in what happens on the ground at the micro level where these processes unfold. This includes, for instance, the reactions of the affected population, the extent of their acquiescence/resistance to these plans, and the strategies they use to hold on to their homes or to bargain for better compensation/resettlement deals (Chakrabarty, 2016). Micro level studies have generally revealed the adverse situation of the resettled population. This is characterized by multiple losses, including loss of homes, livelihoods and community resources, leading to even greater impoverishment after resettlement (Patel; Sliuzas \& Mathur 2015). Case studies from different parts of the country have also pointed to the poor quality of resettled housing units, their small size, and their distance from existing employment sources and schools (Darshini, 2015). Urban sprawl lacks 
the proper documentation and recognition of any knowledge and practice system which ultimately leads the community to the stage of risk, deprivation and vulnerable situations. These situations are the indicators of the insecurity that results in exclusion. It means that the exclusion and marginalization is expressed in the vulnerable and deprived situation of any community. The rational livelihood strategy that is possessed by any community is the key to their sustained socio-economic and political existence. The protection of the skill of any indigenous community is pivotal of the sustainable use of resources (Maskey, 2009). In this context, this study has investigated the urban ways of life that Darai people are experiencing and documented the major socio-economic and political situation. The researcher has attempted to cover the changes from their traditional life style to the changes and modification of their attitudes and thinking toward themselves and their present lifestyle mainly in terms of their exclusion and marginalization.

\section{Urban Development in Damauli}

Within Nepal, there are differences in the process of urban development and its implementation at ground level, reflecting the economic and political requirements of the state, its dominant and competing visions of development. Important for understanding the present situation of Damauli Bazaar is the state's political history. This was marked, following the shifting of headquarter of Tanahun district in 2025 B.S. An official failure to adequately address the needs of Darai ethnic population created situation of inequalities and state of insecurity in the lives of studied community.

\section{Methodology}

This study utilized a mixed-methods design, with data from household surveys, interviews and focused group discussion. Out of 185 Households, the survey involved the purposive sampling of 54 households, some still living in ward no 1,2 and 4. These three words were selected for study because of the remarkable presence of Darai population. It has been studied with Anthropological outlook primarily focusing on social aspects of their life. These areas are also interesting cases as a multiplicity of outcomes reveals the differences within the population of Damauli Bazaar. The survey included 54 households and took place during Jestha and Asar of 2074 B.S. In addition to the survey, a one-hour focus group discussion with 5 people was conducted to understand the processes of urban development and situations of Darai community.

\section{Data Presentation and Analysis}

\section{Unequal Access and Social Life}

Opportunities have been considered the keys of progress and development. Transformation of society into urban area accompanied by vigorous socio-economic conditions can best be materialized creating opportunities. Urbanization in Nepal, however, has faced numerous challenges, including the issues related to health and sanitation, solid waste management, electricity outage, inadequate infrastructure, deteriorating law and order situation, among others (Bhatta, 2012). The study from Vyas municipality has also shown that the exclusion is resulted by the unequal and inadequate access on opportunities. The fact found through study is that social exclusion is a phenomenon distinct from poverty and also distinct from economic inequality. Though, there is an association between the dispersion of incomes and social exclusion, it is not a straightforward one because the relationship is mediated by the experience of common fate, through the sharing of common institutions. Respondents 
in the study area agreed with the creation of economic opportunity after the urban development but were dissatisfied with the distributive pattern of the opportunities. They have realised that the significance of personal income remains in the capacity to share in common institutions. Yam Bahadur Darai replied that the community member has felt gap between the market and community. They have felt humiliation and become backward irrespective of the opportunities of income. The increased wants lured by the availability in market have made Darai community extravagant, imitative and passive in their original social and economic life. According to Yam Bahadur Darai, a master degree holder in Sociology: the opportunities created in the urban areas are the matter of social prestiges. The schools and colleges opened in the urban areas have forced them to abandon and quit their mother tongue. He believes that it is undesirable to forget the Darai Language in current political context.

The move of the ethnic identity has, in his view, became weak pushing them back from the mainstream of ethnic politics in contrary to the inclusive democracy. Inclusive democracy enables participation and for all those affected by problems and their proposed solutions (Yong, 2002). In development discourses social exclusion is predominantly discussed in terms of its relationship with poverty. One reason for the enthusiasm in development studies for social exclusion concepts is its claims to capture both the material and the cultural aspects of deprivation. Social exclusion paradigms place poverty as one element of the marginalization process producing vulnerable groups which experience disadvantage in complex material, cultural and socio-political ways (Jackson, 1999).

Respondents claimed that there is question on the belongingness and durability of ownership over the given opportunities since these opportunities are created by outsiders. In anthropological perspective, the perception, internalization, valuing and response of the community members are keys to take decision regarding the effect of particular circumstances. Following this principle, simply the creations of opportunities are not sufficient condition of incorporation and involvement of the feelings and sentiment of the community members and hence they are excluded. It is true, as I have emphasized, that public policy can make a difference to the impact that any given degree of inequality has on the extent and severity of social exclusion. Nevertheless, in any society in which the great bulk of goods and services are allocated through the market, and in which even those provided publicly can also be bought privately, there must be a close connection between unequally given access and social exclusion.

\section{Everyday Experience and Exclusion}

Community members are to form the sphere through their everyday life accompanied with production, exchange, consumption and storage of resources. The commensality and collectivity of a particular community has been institutionalized in the foundation of above mentioned aspect of lives. The detachment of studied population from the aforementioned aspects has been considered the consequences of detachment from the customary landholding pattern caused by urban development. It has also been explored through a multi-year study of development-induced displacement by the World Commission on Dams (WCD), that the impoverishment and disempowerment have been the rule rather than the exception with respect to affected people around the world. The impact has been felt most heavily, according to the WCD study, in the context of marginalized and vulnerable populations: "Evidence suggests that for a vast majority of the indigenous/tribal peoples displaced by big projects, the experience has been extremely negative in cultural, economic, and health terms. The outcomes have included assetlessness, unemployment, debt-bondage, hunger, and cultural disintegration. For both 
indigenous and non-indigenous communities, studies show that displacement has disproportionately impacted on women and children" (WCD, quoted in Robinson, 2004).

The landholding pattern has been found changed creating undesirable effects and producing unwanted demands among the present generation. The youths are found unwilling to cooperate in the collective matters of Darai population. There is an organization called Darai Samaj (established for the welfare of Darai community) and youths have been found away from its concern and activities. Young generation denies involving in collective functions in a aim to continuity of their cultural sphere due to urbanization process and availability of opportunity of plotting land. $85 \%$ of the respondents replied that the youths are not available to communicate the messages and information regarding meetings and other affairs with in their community. They reported the researcher with the bitter experience that they could not find the people to convey the message of the meetings and discussions of Darai Samaj located in Vyas Municipality - 1, one of the selected study areas. Respondents have made distinction between Sanskriti and Bikriti and they are seen to have been isolated and dislocated from their spaces and spheres. They have seen opportunities but are placed far from the utilization. Indra Bahadur Darai, the ex-chairman of ward no-4, reported that: Municipality did not provide desirable opportunities in justbased way. It is claimed with the only 8 people being involved in government job. Though the Darai are the old settlers and Adivasi of Damauli Bazaar, in the view of Indra Bahadur, it is unfortunate that they are not given even the information. The kinship bond found previously in the Darai community has been broken today due to lack of close interactions that is caused by the process of urbanization.

Even in the presence of some physical amenities, Darai people now have realized the social distancing.

\section{Cultural Contact and Sense of Social Exclusion}

Urban development has contributed as an influencing factor of migration responsible to exclude the studied ethnic community via the disappearance of the indigenous culture and practice. Migration of non-Darai communities such as Newar, Brahmin, Chhetri, Gurung in study area changed the scenario in 2030 B.S. The process of migration that promoted urbanization excluded Darai community. The District Panchayat made a decision according to which all the land holders now were forced to make even a hut on their land. It was the initiation of the flow of migration and emergence of multicultural societies. Then, contact of multiple cultural entities in Damauli changed the previously single cultural structure. Therefore, Cultural norms and values of Darai community have been collapsed as the outcome of urban development one respondent said: All the planned land was sold to the outsiders. There was involvement only of the outsiders. The old settlers Darai were excluded from the process of land acquisition and planning. We also were not familiar with the future of planned and urban settlement. Few of the Darai had asked for the land but could not get. If the land would have been given to Darai too, we would also have the role in politics of district. Our culture also would have been protected. It would be the pleasure of us. Now we are forced to assimilate ourselves in undesirable situations. Migrants and merchants have majority. They have captured the power of the Bazaar. They have cheated and exploited us. We have no trust on our own community members. Present generations have forgotten even the funeral practices. Now they imitate the practice of Brahmin, Chhetri, Newar and other non-Darai communities. 
Social exclusion, fragmentation, and disconnection are experiences shared and internalized by the Darai community members. The social exclusion is not simply the situation but it is also an experience and this sort of meaning was given from the respondents. Through this process people are cut off from their institutions and services, social networks and opportunities that the great majority of society enjoys (Pierson, 2002). The degree and the extent of the exclusion and isolation of Darai community residing in Damauli Bazaar (Vyas Municipality, ward no 1, 2, and 4) have been reflected in the detachment of studied population from their typical, identical and worthy cultural practices. Dirgha Bahadur Darai, another key informant reported:

The Darai people have now been socially and culturally excluded since they are unable and not interested to practice the customary cultural processes and ceremonies. They have now lost the cultural space to form the distinct identity and meaning of their lives due to the condition of cultural contact.

He proposed that each person in each community is free to exercise skill and knowledge as his intellectual activity, the fundamental to human experience, creating separate but central position in socio-cultural and political dimension. Through ethnographic description, researcher has explored the ways and extents of exclusion of Darai community in reference to the notable response of Dirgha Bahadur Darai that urbanization and expansion of other sources of recreation have caused elimination of seasonal and periodical dance, songs, gatherings and the cultural institution such as Rodhi. Darai people took these practices as the means of social solidarity and social capital. It has been reported that there was a fundamental practice of performing the dance and cultural ceremonies in the home of Mukhiya as per his interest. That system and tradition, to the opinion of respondents, had maintained the social leadership and control. It had equally developed the feeling of reverence, faith and respect in the community. It was equally functional to promote the trusteeship, friendship, and belongingness within the community members. All these social assets and distinct features of Darai community has collapsed and dead as the consequences of urban development and migration of non- Darai communities. Sharing the bitter experience of the miserable situation of identical socio-cultural practices, a respondent anonymously told: His neighbor did not perform the funeral of his father as per their traditional culture. He lived in mourning for thirteen days as Brahmin and Chhetri use to live. It is extreme violation of the rule of Darai community. He was planning to talk in the meeting of Darai Sewa Samaj but could not speak even a word because of possible negative response and divisions in the community. Now the fear and terror of the isolation has grown in our urban settlement.

Darai have been forced to abandon their mother tongue in the name of competition irrespective their interest of the continuity and promotion of their own language. Considering identity as a category of practice embedded within multidimensional relations of power, they need struggle for their social and political position in the modern system. Despite of their internalization, they have found themselves incapable and imperfect in current complex urban structure. According to Cheej Bahadur Darai, they are following the cultural life of Brahmin and Chhetri who were migrated after the land planning that has humiliated them today.

\section{Urbanization and Rise of Ethnic Tension}

Ethnic tension can be understood as the extent of social exclusion. It has also been seen as the consequences of social exclusion. Ethnic tension is another reality found among the studied population 
that they have been indulged in fight, quarrels and groupism. Khar Sing Darai, a social worker and leader, responded that the youths of community have fought against non-Darai people. The migrants in Bazaar area have become the major part of the workforce in market. The urban people and governmental bodies have used authoritarian language that has caused the extinction of Darai language leading to the ethnic tension. It has become problem to accommodate and recognize the cultural diversity in urban areas. This is the construction of reality analyzing the individual experiences, emotions and feelings of Darai community. The rapidly growing extra demand among the young generation has created tension in Darai community. Urban areas are now increasingly the sites of humanitarian crisis resulting from natural hazards, conflict and displacement however the goal 11 of the Sustainable Development Goals (SDGs (UN 2015)) aims to make cities and human settlements 'inclusive, safe, resilient and sustainable' by 2030 They are found worried of the maintenance of gap between income and needs. Cheej Bahadur Darai responded that: The Darai community suffered disintegration of family. A woman was living with her son and daughter. Her husband had gone to abroad for employment. She had got money from her husband. She should not have to work to earn money and manage resources for her survival. She used to send child in school. She was free to go outside the home in day time and come at evening in the time. She lived a very comfortable life. She had a big house. But she sold the house in forty-five lakhs and got married with another man and left the bazaar. After that incident, his family members and community people are worried about the future of community and their children.

Another tension found among Darai community is regarding the competition in the context of preservation of indigenous culture including language and utilization of opportunities. They have faced dilemma whether to continue Darai language even in the conversation among family members or not. The reason is that the use of Darai language certainly places them behind in global competition and priority to another secondary language further excludes the Darai community. It has resulted the domain of cultural politics of Darai community in stake. The Darai community now has been found vulnerable lacking the domain of negotiation for their space. Another field of ethnic tension among studied population is the negligence of young generations in participation of different cultural functions of Darai community. Cheej Bahadur Darai and Padam Bahadur Darai both have shown their major concern on the detached motive of youths. Nevertheless, The attempts to bring the youths to adhere to the cultural mainstream have been meaningless. Urban development and migration of non-Darai community have been responsible factor for their tension as claimed by 98 percent of respondents.

\section{Ethnic Tension and Ethnic Experience}

Ethnic tension and ethnic experience are considered the pivotal of the study of factor and the extent of exclusion of Darai ethnic population in studied area. Ethnic experience and tension in relation to the position and role of Darai community of studied area have been brought under the scope of politics of culture of Darai community leading to the search of space for negotiation and bargaining aiming to the formation of social space, meanings of life and reality. The degrees of tension in the level of inter and intra both have made Darai people think about their poor position within the social structure. The everyday experiences of respondents have placed them in the lower strata of the social, economic and political ladder. They are found themselves inefficient to bargain and negotiate for their basic rights. Despite their long and very old history of settlement and land ownership, they are left with isolation and helplessness in their native land. The inter-ethnic conflict has made them inferior 
and looser and intra-ethnic conflicts have made them experience the rent seekers community. Yam Bahadur Darai shared that: Young people of Darai Community have become the agents of land brokers who are outsiders. They have earned a lot of money with the support of our youths. They have lured the youngsters. Darai people living in the same communication can't share the matters and feelings now. There is lack of supportive hands for the community but brokers have got every support easily. It is very disgraceful to Darai community. We need third hand to get contribution and help from our own community members. The urban facilities and the increased value of cash killed the simplicity of the Darai people. We people now do not produce grains even from the fertile land. Our consumption pattern also has been changed. We had sufficient food grains in the past. We were the producers but now we are only consumer.

\section{Conclusion}

In this paper, researcher has explored an important issue in the context of a lower-income country undergoing fairly rapid urban transition - namely, urban development-induced displacement and its impact on the quality of lives of affected population over the longer term. The process of urbanization has weakened solidarity and created tensions among the people of Darai community and led to further exclusion. This paper has highlighted the need to look at both the households that have been uprooted and remained in place, in order to understand the consequences of the impacts of urban development more fully. While there are ongoing problems there with sanitation and long-term security, this community has experienced more fear of social division and gradual degradation in the quality of their living conditions.

\section{ACKNOWLEDGEMENTS}

We would like to thank Bishow Neupane and Khar Singh Darai for assistance in household survey, collecting data and organizing the focus group discussion. We also thank Karna Bahadur Adhikari for providing very critically important information on the process of planned settlement and urban development in Damauli. Finally, We would like to thank two anonymous referees of the paper and the journal editors for their constructive suggestions that helped us to increase the quality of this paper.

\section{REFERENCES}

Bhatta, K. (2012). Dynamics of Urbanization in Nepal: The Role and Response of Local Government. Alliance for Social Dialogue Policy Research Fellowship Program. December 2012.

Brokensha, D. (1980). Indigenous Knowledge Systems and Development. Lanham,USA: University Press of America.

Bray, D. V., and Velazquez A. (2009). Conservation and Society. Department of Earth and Environment, Florida International University, Miami, USA.

Chakraborty, A (2016), "Of slime moulds and smart slums: Kolkata informal settlements and the tale of a failed canal reclamation project”, Environment and Urbanization Vol. 28, No 2, pages 553-568.

Cernea, M. (2005). Restriction of Access' is Displacement: A Broader Concept and Policy. Forced Migration Review, 23:48-9.

Dahit, G. (2009). Social Inclusion/ Exclusion in Relation to Tharu Indigenous Knowledge and Practices. Social Inclusion and National Building in Nepal. Social Inclusion Research Fund. Hissi Offset Printers. 
Holmberg, D. (2010). Cultural Rights in the Residues of an Irreversible History. Nepal.

Horowitz, L. S. (1998). Integrating Indigenous Resource Management with Wildlife Conservation: A Case Study of Batang Ai National Park, Sarawak, Malaysia. Human Ecology 26:371-403.

Jackson, C. (1999). The European Journal of Development Research Vol. 11. No.1. Frank Cass. London. Lama, M. (2014). The Social Inclusion Atlas of Nepal and Ethnographic Profiles. Perspectives on social Inclusion and Exclusion in Nepal. Central Department of Sociology/Anthropology Tribhuvan University.

Mahadevia,D. (2015), Shelter Security in Urban India: Pathways, Barriers and Outcomes, Concept Publishing Co, New Delhi.

Maskey, S. (2009). Indigenous Knowledge System as Resource for Sustaining Raji Work and Life: A Case Study of Surkhet District. Social Inclusion and National Building in Nepal. Social Inclusion Research Fund. Hissi Offset Printers.

Orlove, B. S. and Stephen B. B. (1996). Anthropology and the Conservation of Biodiversity in Annual Review of Anthropology.

Patel, S., Richard S. and Mathur, N. (2015), "The risk of impoverishment in urban developmentinduced displacement and resettlement in Ahmedabad", Environment and Urbanization Vol 27, No 1, pages 231-256.

Pierson,J. (2002). Tackling Social Exclusion. Community Care. Routledge.

Rittel, Horst W J and Melvin M Webber (1973), "Dilemmas in a general theory of planning”, Policy Sciences Vol 4, pages 155-169.

Robinson, W. C. (2004). "Minimizing Development-Induced Displacement ", available at: http://www. migrationinformation.org/feature/display.cfm?ID=194.

Room, G. et al. (1992). Observatory on National Policies to Combat Social Exclusion. Second Annual Report. Brussels, Directorate General for Employment, Social Affairs and Industrial Relations, Commission of the European Committee.

Roy, Dunnu (2008), “Urban development projects and displacement of the poor", in Hari Mohan Mathur (editor), Social Development Report 2008: Development and Displacement, Oxford University Press, New Delhi, pages 141-154.

Sen, A. (2000). Social Exclusion: Concept, Application and Security. Office of Environment and Social Development. Asian Development Bank (Social Development Papers no 1). Master of trinity College Cambridge and Lamont University.

Subba, B. (2009). An Evaluation of Government and Donor Policies towards Indigenous People. Social Inclusion and National Building in Nepal. Social Inclusion Research Fund. Hissi Offset Printers.

UN (2015), 'Transforming Our World: The 2030 Agenda For Sustainable Development',A/RES/70/1. https://sustainabledevelopment.un.org/content/documents/21252030\%20Agenda\%20for\%20 Sustainable\%20Development\%20web.pdf.

Van Doninck, Nele (2013), “'We live like birds in a cage': negotiating forced inclusion in a resettlement colony in Kolkata, India", Master's thesis, Master of Science in Social and Cultural Anthropology, KU Leuven, Leuven, available at http://www.scriptiebank.be/sites/default/ files/ THESIS\%20(nvd).pdf.

Young, I. (2000). Inclusive Democracy. Oxford University Press. New York. 